\title{
The evolution of interferon-tau
}

\author{
Alan D Ealy and Lydia K Wooldridge \\ Department of Animal and Poultry Sciences, Virginia Tech, Blacksburg, Virginia, USA \\ Correspondence should be addressed to A D Ealy; Email: ealy@vt.edu
}

\begin{abstract}
Thirty years ago, a novel type I interferon (IFN) was identified by molecular cloning of cDNA libraries constructed from RNA extracted from ovine and bovine pre-implantation embryos. This protein was eventually designated as IFN-tau (IFNT) to highlight its trophoblast-dependent expression. IFNT function is not immune related. Instead, it interacts with the maternal system to initiate the establishment and maintenance of pregnancy. This activity is indispensable for the continuation of pregnancy. Our review will describe how IFNT evolved from other type I IFNs to function in this new capacity. IFNT genes have only been identified in pecoran ruminants within the Artiodactyla order (e.g. cattle, sheep, goats, deer, antelope, giraffe). The ancestral IFNT gene emerged approximately 36 million years ago most likely from rearrangement and/or insertion events that combined an ancestral IFN-omega (IFNW) gene with a trophoblast-specifying promoter/enhancer. Since then, IFNT genes have duplicated, likely through conversion events, and mutations have allowed them to adapt to their new function in concert with the emergence of different species. Multiple IFNT polymorphisms have been identified in cattle, sheep and goats. These genes and gene alleles encode proteins that do not display identical antiviral, antiproliferative and antiluteolytic activities. The need for multiple IFNT genes, numerous alleles and distinct activities remains debatable, but the consensus is that this complexity in IFNT expression and biological activity must be needed to provide the best opportunity for pregnancy to be recognized by the maternal system so that gestation may continue.

Reproduction (2017) 154 F1-F10
\end{abstract}

\section{Introduction}

In nearly every eutherian mammal, pregnancy can only be maintained if progesterone production continues beyond the length of a normal estrous or menstrual cycle. This requires that the ovarian structure producing progesterone, termed the corpus luteum $(\mathrm{CL})$, must remain active either throughout gestation or until the placenta produces sufficient progesterone. Rescuing the $C L$ is achieved in various ways. Higher primates, for example, produce chorionic gonadotrophin (CG; hCG in humans) to maintain CL function. Sheep, cattle, goats and presumably other pecoran ruminants rescue $C L$ function by preventing the pulsatile release of uterine prostaglandin F2 $\alpha$ (PGF2 $\alpha$ ), the luteolytic agent that causes CL regression (Spencer et al. 2004, Roberts et al. 2008). This event is one critical feature of physiological adjustments the maternal system must make in order to accommodate pregnancy. These maternal adjustments to pregnancy are generally referred to as maternal recognition of pregnancy.

Moor and Rowson initially investigated maternal recognition of pregnancy in ruminants by completing embryo recovery and transfer studies in sheep and cattle (Moor \& Rowson 1964, 1966, Rowson et al. 1969, Lawson et al. 1975). This work defined the critical window of pregnancy recognition in these species and suggested the active factor was proteinaceous.
The protein inferred responsible for this activity was given a number of names, which included trophoblastin, protein- $X$ and trophoblast protein-1 (oTP1 and bTP1 for ovine and bovine counterparts respectively) (Martal et al. 1979, Godkin et al. 1982, 1984a). Functional studies also were completed, where either protein extracts from pregnant uterine flushes or purified proteins from short-term ovine conceptus cultures extended CL function for several days to a few weeks (Rowson \& Moor 1967, Martal et al. 1979, Godkin et al. 1984b). This antiluteolytic activity and various additional pregnancy-based biological activities for IFNT have been described in several recent reviews, including three in this special issue (Spencer \& Hansen; Forde \& Lonergan; Bazer \& Thatcher).

In 1987, cDNA screening and sequencing using an ovine conceptus cDNA expression library and oTP1 antibody uncovered this maternal recognition of pregnancy factor as a type I IFN (Imakawa et al. 1987). Soon thereafter, cDNA screening for the sequence encoding ovine trophoblastin revealed that it represented the same protein (Charpigny et al. 1988). Screening a bovine cDNA conceptus library determined that bTP1 also was a type I IFN (Imakawa et al. 1989). At the time when the identity of IFNT was revealed, IFNs were thought of solely as antiviral and immune-regulatory agents. The IFN field had developed to the point where

This paper is part of an Anniversary Issue celebrating 30 Years of Interferon-Tau The Guest Editor for this section was Professor R Michael Roberts. 
numerous IFNs had been well established as antiviral agents and were being considered as therapies for various viral infections and cancers (Pestka et al. 1987). It was a considerable surprise when the pregnancy recognition factor for ruminants was identified as a type I IFN. In fact, this finding was challenged, arguing that a type I IFN could not function as an essential hormone of pregnancy because fertility was not compromised in mice lacking components of IFN signaling (Roberts et al. 1998). Much has been learned since this point, including that the mouse cannot be used as model to study pregnancy recognition in ruminants.

This review will describe how this unique subclass of IFNs emerged from other type I IFNs. We also will speculate why IFNT was selected to serve as the maternal recognition of pregnancy factor in ruminants. Several excellent reviews already exist on this topic (Roberts et al. 2003, 2008). This article will summarize that information and provide additional insights into what has been learned and what still remains unclear about the evolution of IFNT.

\section{Interferons}

Three main subclasses of IFNs exist. These are classified as type I, II or III IFNs. The type I IFNs are composed of at least 9 distinct subfamilies: IFN-alpha (IFNA), beta (IFNB), delta (IFND), omega (IFNW), epsilon (IFNE), kappa (IFNK), tau (IFNT), zeta (IFNZ) and X (IFNX) (Krause \& Pestka 2005, Walker \& Roberts 2009). The type I family likely emerged from the type III IFN family, which is described below, as mammalian lineages diverged from avians and reptiles $~ 300$ million years ago (Hughes 1995, Levraud et al. 2007). Seven of these nine IFN subfamilies have been identified in the bovine genome (IFNA, IFNB, IFNE, IFNK, IFNW, IFNT, IFNX) (Walker \& Roberts 2009). The selectivity of most IFN responses are governed by tissue-dependent expression and type of pathogen encountered. The IFNA and IFNB subfamilies are often referred to as immediate viral responders. Many cell types produce IFNA in response to various stimuli, whereas IFNB is primarily secreted from fibroblasts (Pestka et al. 2004). Most of the remaining type I IFNs appear to have more specialized niches, either by their production in specific cell types or by their involvement with reacting to specific types of viruses (Pestka et al. 2004).

Two IFNs, IFND and IFNT, are not regulated principally by responding to viral infections but rather are expressed constitutively by pre-implantation conceptuses of pigs and ruminants respectively. IFND is not responsible for pregnancy recognition in pigs, but it may have important auxiliary roles in maintaining pregnancies (Lefevre et al. $1998 a, b)$. IFND emerged in mammal genomes much earlier than IFNT, and it is not a direct ancestor of IFNT (Cochet et al. 2009). Noteworthy features about IFND gene retention in mammals and its potential biological functions during pregnancy in pigs have been described elsewhere (Roberts et al. 2008, Sang et al. 2014).

All type I IFNs exert their actions through interaction with the same receptor complex (Roberts 2007, Roberts et al. 1992a). These receptors are termed IFNA receptors (IFNAR). They are composed of two heterologous subunits, termed IFNAR1 and IFNAR2. Receptors mediate transcription by controlling the activity of Janus kinases and signal transducers of transcription (JAK-STAT) (Roberts 2007). These receptors confer all the activities for type I IFNs throughout the body, including the IFNT signals generated within the epithelial and stromal endometrium in ruminants ( $\mathrm{Li} \&$ Roberts 1994a).

Type II IFN is represented by a single IFN, known as IFN gamma (IFNG). IFNG contains antiviral, antitumor and immune-modulating activities and is required for innate and adaptive immunity against viral and bacterial infections, but it is best known as an inflammatory and autoimmune cytokine (Bach et al. 1997, Billiau \& Matthys 2009). IFNG has no structural similarity with type I or III IFNs. It is derived from a single gene, functions as a homodimer and acts through a receptor complex distinct from those utilized by type I IFNs (Billiau \& Matthys 2009).

Less is known about the type III IFN family due, in part, because members of this grouping are not present in all mammals (Galani et al. 2015). There are three members of this family in humans. These are known either as IFN-lambda (IFNL) 1, 2 and 3 or interleukin (IL) 29, 28A and 28B. These IFNs share low structural similarity with type I IFNs and IL10 (Gad et al. 2009). They utilize a receptor complex that differs from that used by type I IFNs (Sheppard et al. 2003). This receptor complex contains a specific, unique alpha subunit and a common IL10 beta subunit. This class of IFNs likely only plays a minor role in controlling viral infections (Ank et al. 2008), although it has been implicated in the viral defenses of the human placenta (Bayer et al. 2016).

\section{The origins of IFNT}

All type I IFN genes reside within a specific locus on chromosome 8 in cattle (Walker \& Roberts 2009). IFNT shares its greatest sequence identity with IFNW $(\sim 70 \%$ amino acid (AA) identity) and contains only moderate similarity with IFNA ( 50\% AA identity) and low similarity with IFNB ( 25\% AA identity) (Leaman et al. 1992, Roberts et al. 1992b). Although the primary AA sequences of type I IFNs differ, each of these IFNs possesses a similar secondary and tertiary structure. Conserved cysteine residues exist in all IFN subclasses, and disulfide bonding and conservation of five alpha helices arranged in an antiparallel manner and connected by definitive loop regions produces similar 


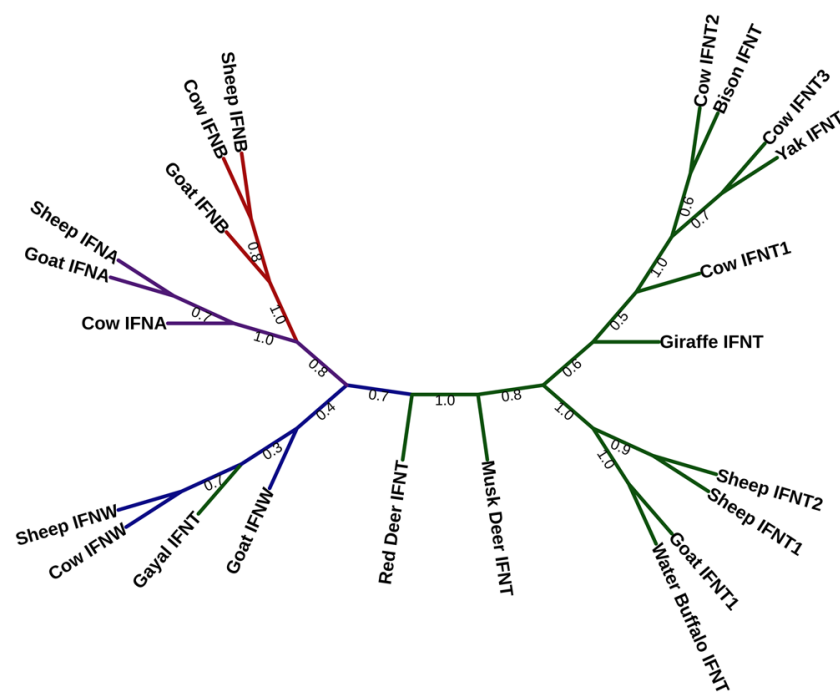

Figure 1 Phylogenetic analysis of nucleotide coding sequences from representative IFNA, IFNB, IFNW and IFNT genes in various ruminant species. The identity of each gene used for this analysis is provided in Supplementary Table 1. Genus/species: Bison bison (Bison, American) Bos Frontalis (Gaur, Mithun, Gayal), Bos grunniens (Yak, domestic), Bos taurus (Cow), Bubalus bubalis (Water buffalo), Capra hircus (Goat), Cervus elephus (Red deer), Giraffa camelopardalis (Giraffe), Moschus berezovskii (Musk deer, dwarf), and Ovis aries (Sheep). The entire coding region sequences (signal peptide plus mature protein) were analyzed using Molecular Evolutionary Genetics Analysis version 7 software (MEGA7) (http://www.megasoftware.net/). Maximum Likelihood analysis was completed using the Bootstrap method with 2000 replicates using the Tamuar-Nei model (Tamura \& Nei 1993). Trees were developed using the Interactive Tree of Life version 3 software (Letunic \& Bork 2016).

binding domains for type I IFN receptors (Roberts 2007, Roberts et al. 1992a).

A phylogenetic tree (Fig. 1) shows the probable evolutionary relationships between representative IFNT-coding region nucleotide sequences from several ruminant species and representative IFNTA, IFNB and IFNW genes from the cow, sheep and goat. Clustering of the four major IFN classes is evident, with one exception. Gayal IFNT (Bos frontalis, Mithun) associates more closely with IFNW genes instead of the remaining IFNT genes. There is low confidence in where this specific IFNT should be placed. Bootstrap values, which indicate the probability of proper placement within the phylogenetic tree, offer a low statistical likelihood of its exact location. Usually bootstrap values $\geq 0.7$ is needed to have confidence that genes are inserted in the proper location within the tree. The bootstrap value for Gayal IFNT is 0.3 (Baldauf 2003). Also, this sequence was derived from genomic DNA, and its trophoblast-dependent expression remains uncertain (Rajaravindra et al. 2006). Therefore, this gene may well be an IFNW, of which there are $>20$ members in cattle (Bos taurus) (Walker \& Roberts 2009), although an examination of the $5^{\prime}$ untranslated region (UTR) of this gene is needed before it can be correctly identified as an IFNT or IFNW. As will be discussed soon, the IFNT promoter/enhancer region is vastly different from IFNW.

Four of the five pecoran ruminant families are represented in this phylograph. The IFNT genes for red deer (Cervidae family), musk deer (Moschidae family) and giraffe (Giraffidae family) are contained in definitive evolutionary branches, as expected, and the remaining Bovinae (bison, cow and domestic yak) and Caprinae (sheep, goat) subfamily members of the Bovidae family cluster into two other major branches. The close relationship between the cow IFNT2 gene and the American bison gene may reflect inter-genus breedings. The present-day bison genome contains bovine ancestry because of accidental and intentional matings over the past several hundred years (e.g. Beefalo) (Hedrick 2009). Only $1.5 \%$ of all plains bison are predicted to be free of domestic cattle ancestry (Freese et al. 2007). The inter-genus association between the water buffalo IFNT sequence with the goat sequence cannot be explained. The presence of IFNT genes in the final ruminant family, the Antilocapridae, has not been investigated. The pronghorn is the only living species in this family.

The main distinguishing feature between IFNT and most other type I IFNs is its unique, trophoblastspecific expression in ruminant species. The first 400 bases upstream of the IFNT gene transcription start site are unique to IFNT, and this region lacks any apparent virus-inducible transcriptional elements (Leaman et al. 1992). Several trophoblast-specifying transcriptional control elements exist within this $5^{\prime}$ promoter/enhancer region, including ETS2 and DLX3 (Ezashi et al. 1998, Imakawa et al. 2006). This unique 5' UTR may restrict IFNT transcription to trophoblast cells, the outermost cells of a developing conceptus that will develop into the outermost layer of the placenta. In bovine embryos, expression begins as the trophoblast lineage emerges at the morula and blastocyst stages (day 6-7 of pregnancy in cattle) and continues until trophoblast cells begin adhering to the uterine epithelium ( day 16 in cattle) (Ealy et al. 2001, Kubisch et al. 2004). The production of IFNT is small at the morula and blastocyst stages but increases as conceptus elongation occurs (day 14-17 in cattle). The control of IFNT expression is covered in greater detail in a companion review article (Ezashi \& Imakawa).

Another distinguishing feature of IFNT is its unique 3' UTR. The proximal 300 bases of the 3' UTR are highly conserved in IFNT (Leaman et al. 1992). The conservation with IFNW sequences ends approximately 120 bases downstream of the translational stop codon (Leaman et al. 1992). The functional significance of this unique $3^{\prime}$ UTR is unclear. At least two micro-RNA (miRNA) target sequences exist within the $3^{\prime}$ UTR of bovine and ovine IFNT, and at least one of these miRNA is differentially expressed in bovine conceptuses during early pregnancy (Yang \& Ealy Unpublished observations). 
However, it is not clear if miRNAs exert any control on IFNT production in ruminants.

Based on the observations that IFNT is similar in coding sequence to IFNW but different in its $5^{\prime}$ and 3' UTRs, we predict that the ancestral IFNT gene was created from rearrangement or insertion events, where an IFNW gene was combined with a novel, trophoblastspecifying $5^{\prime}$ UTR and a distinct 3' UTR. The timing of these rearrangement events is predicted to have occurred around 36 million years ago (MYA) (Roberts et al. 1997), which coincides with the deviation of Ruminantia suborder from Suiforme (swine) and Tylopoda (llamas, camels) suborders of Artiodactyla (Roberts et al. 1998). Initial indications that IFNT was restricted to ruminant species were observed by using Southern blot analysis (Fig. 2) (Leaman \& Roberts 1992). Use of a 3' UTR ovine IFNT probe to distinguish IFNT from what we now know to be numerous IFNW provided the first evidence that IFNT was unique to the ruminant species (Fig. 2). In most cases, multiple bands were detected within these species, while there was no hybridization to DNA from other mammalian taxa. Subsequent whole genome sequencing has confirmed this ruminantspecific inference.

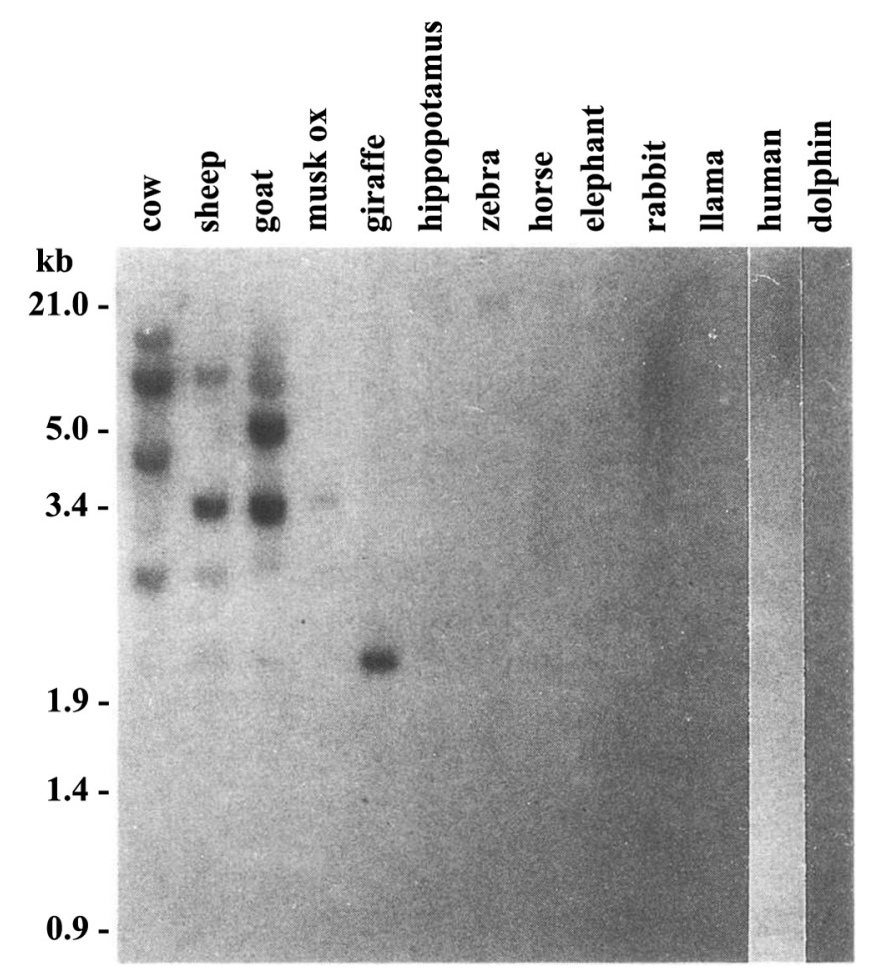

Figure 2 Genomic Southern Blot analysis of gene distribution for IFNT genes in various species (Zoo Blots). DNA (3-8 4 g) from indicated species was digested with EcoR1, electrophoresed, transferred to a nylon membrane, and hybridized with an $O$. aries IFNT probe derived from the 3' UTR region. Molecular sizes are indicated in kilobase $(\mathrm{kb})$ pairs. This figure was taken from (Leaman et al. 1992).

\section{Interferons at the placental-maternal interface}

The evolution of maternal recognition of pregnancy signals has not been defined in many species, but what is known is that these signals usually are derived from the trophoblast cell, are highly variable, and they appear to be evolving rapidly (Roberts et al. 2016). For example, higher primates and Suinae, both of which lack IFNT, utilize CG and estrogens respectively, as their pregnancy recognition factors. The early timing of implantation and extensive eroding of the endometrium for intimate access to maternal blood permits hCG to act as an endocrine-mediated luteotrophic factor for humans. By contrast, no endometrial erosion occurs in the pig placenta, and estrogen must diffuse into the maternal bloodstream. Estrogens also function locally within the uterus to prolong CL lifespan (Bazer 1989, Ziecik 2002).

Maternal recognition of pregnancy is very different in ruminants. One notable feature of conceptus development in these species is that implantation is delayed until after maternal recognition of pregnancy has taken place. Like other ungulates (Perisodactyla and Artiodactyla), ruminant conceptuses remain freefloating after hatching from the zona pellucida (day 8-10 of pregnancy in cattle). Intimate contact with the uterus does not occur until on or after day 16 of pregnancy in cattle (Bazer et al. 2009). This requires the development of a very different pregnancy signal, one that can function locally within the uterus instead of systemically. The evolution of IFNT has satisfied this role in ruminants, but other ungulates utilize different signals. As mentioned above, the pig utilizes estrogens secreted from trophoblast cells during early pregnancy as their antiluteolytic signal (Bazer 1989). The pregnancy recognition signals utilized by most other ungulates have not been described, but those that have been studied thus far, such as the horse (Klein \& Troedsson 2011), not utilize either an IFN or a steroid hormone to confer pregnancy recognition.

The selective pressure to utilize such unexpected and unique factors as maternal recognition of pregnancy signals likely occurs because of selective pressures placed onto mammals to diversify placental types. Maternal control of metabolic resource management is one of the best explanations for why so many different placental types exist in mammals (Fowden \& Constancia 2012). This is one aspect of what is conventionally termed the genetic conflict theory, where females seek to balance available resources with reproduction to maximize the dissemination of their genetics to future generations (Crespi \& Semeniuk 2004). The vast array of placental types that exist in mammals likely represents the various ways that maternal and fetal systems have evolved to provide sufficient maternal resources without compromising maternal health and survival. Another probable reason for placental evolution is for avoidance of immune rejection (Hemberger 2013). Processes 
utilized to achieve this are not well understood, and they likely differ as the degree of intimacy between the fetus and maternal system changes.

The development of IFNT as the pregnancy recognition of pregnancy in ruminants may have occurred because IFNs were already serving facilitative roles during gestation, and ancestral ruminants modified the role of IFNs for a new purpose, one that required it to sustain pregnancy. Antiviral activity, suggestive of IFN production, or transcripts for other type I IFNs have been detected from pre-implantation stage conceptuses in several species, including mice, horses and pigs (Cross \& Roberts 1989, Cross et al. 1990, Cochet et al. 2009). Although the expression of IFNs at the maternalplacental interface made it possible for a progenitor IFNT to emerge as a pregnancy recognition factor, a more difficult question to answer is how IFNT evolved to act in this manner (i.e. as an antiluteolytic agent). It is not clear how this progenitor IFNT made the leap from being an antiviral agent to gaining the ability to blunt uterine prostaglandin release. Perhaps the pro-inflammatory and pro-immune features of prostaglandins offered the opportunity for IFNT to make this switch (Hansen 1997).

\section{The multiplicity of IFNT genes and alleles}

Cattle contain at least 13 IFNA, 6 IFNB and 24 IFNW genes (Walker \& Roberts 2009). The exact number of IFNT genes in ruminants remains debatable, but multiple genes are certain when examining genomic DNA hybridization studies (Fig. 2) and more recent genome sequencing analyses (Walker \& Roberts 2009). Only three IFNT genes are annotated in the current bovine genome assembly (UMD 3.1.1). We contend that additional genes will be detected as the bovine genome becomes more completely annotated. A careful examination of the bovine genome revealed 45 distinct IFNT sequences (Walker \& Roberts Unpublished observations). The $\sim 7$-fold depth of coverage for this genome would place the average genome read number at between 6 and 7 IFNT genes. Supportive evidence of this is seen when examining transcript variants from individual conceptuses (Walker \& Roberts 2009). At least 6 different IFNT variants are expressed in individual bovine conceptuses and from a bovine trophoblast cell line (CT1) derived from a single blastocyst. Some of these variants may be allelic. It is also possible that the number of IFNT genes may vary among individuals and breeds.

There are many examples of gene family expansions, but the process appears to be particularly common for families whose members are expressed in the placenta (Rawn \& Cross 2008, Roberts et al. 2016). Examples include (1) growth hormone-related and prolactin-related proteins found in primates, rodents and ruminants, (2) the CG beta gene family in primates,
(3) pregnancy-specific proteins found in primates and rodents, (4) pregnancy-associated glycoproteins found in ruminants and swine and (5) IFNT in ruminants. Having several IFNT genes may provide extra expression when a massive boost in IFNT is needed when the $\mathrm{CL}$ of pregnancy is hovering on the brink of luteolysis. On the other hand, duplication will ultimately lead to redundancy, such that unnecessary genes can be simply be eliminated without consequence. Occasionally, however, such redundancy may allow a duplicated gene time to acquire mutations that improve old functions and even acquire new ones (Hughes 1995). A similar process operating on an ancestral IFNW probably allowed such a gene to acquire trophoblast-specific regulatory regions and evolve into what we now know as IFNT.

Several IFNT gene variants have been described in cattle, sheep and goats. It is not clear whether these variants represent individual genes or allelic variants of a few genes. Figure 3 illustrates a phylogenetic tree that includes every unique IFNT sequence deposited in the GenBank database for the cow, sheep and goat. This analysis predicts how variants likely evolved from each other based on the number and location of individual nucleotide changes. Nucleotide sequences

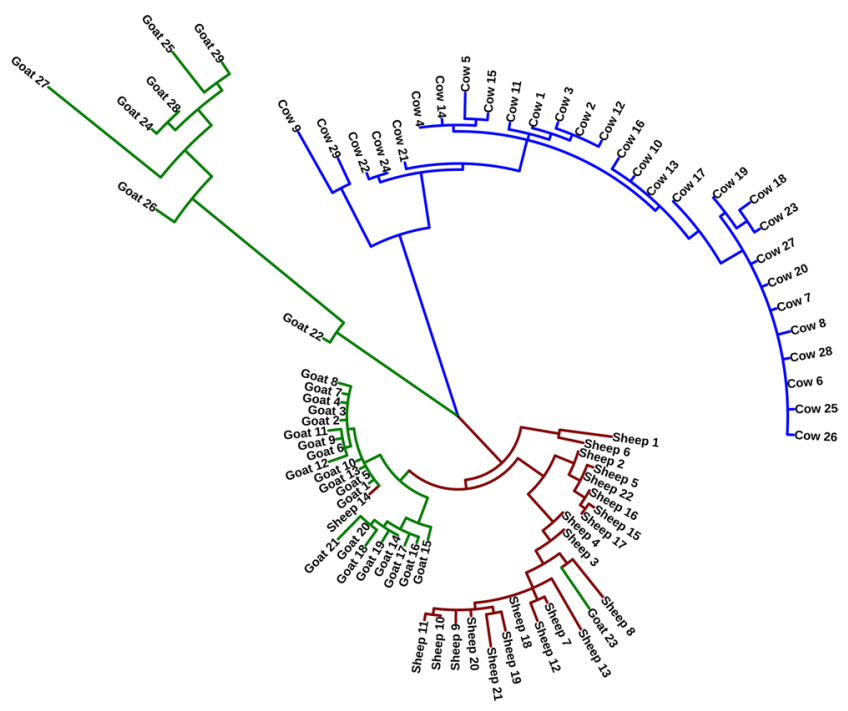

Figure 3 Phylogenetic analysis of nucleotide coding sequences for all polymorphic forms of IFNT available in the GenBank database for cattle (B. taurus), sheep (O. aries) and goat (C. hircus). The identity of each gene used for this analysis is provided in Supplementary Table 2. The coding regions without their signal peptide regions (i.e. mature peptide only) were analyzed using Molecular Evolutionary Genetics Analysis version 7 software (MEGA7) (http://www. megasoftware.net/). Maximum Likelihood analysis was completed using the Bootstrap method with 2000 replicates using the TamuarNei model (Tamura \& Nei 1993). Trees were developed using the Interactive Tree of Life version 3 software (Letunic \& Bork 2016). The Bos taurus IFNT1, IFNT2 and IFNT3 genes are represented by cow sequence\# 9, 1 and 6 respectively. The Ovis aries IFNT1 and IFNT2 genes are represented by sheep sequence $\$ 5$ and 9 respectively. The Capra hircus IFNT gene is represented as goat sequence\# 1 . 
were examined rather than AA sequence divergence in order to obtain a more complete picture of IFNT gene variant evolution and to strengthen their correct placement within the tree (Baldauf 2003). Since an exact identity of these variants is not required for this discussion, variants were given arbitrary numbers to identify them (Supplementary Table 2 for the GenBank accession number key, see section on supplementary data given at the end of this article). Eighty-one sequences were evaluated: 29 in the cow, 23 in the sheep and 29 in the goat. Eighteen bovine, 12 ovine and 10 caprine IFNT variants were validated by their detection in multiple RT-PCR reactions from identical samples. These observations rule out the possibility that the nucleotide changes were acquired during amplification. The remaining variants have not gone through this validation process, and so, it is not certain if their mutations are represented in the cow, sheep and goat genomes or if they represent mutations introduced during RT or PCR. Their inclusion was chosen in order to present the most extensive depiction of IFNT polymorphisms.

Clear distinctions between the three species are evident. Only two variants did not segregate within their respective species (sheep 14 and goat 23). The most obvious example of gene clustering occurred in the goat, where major groups of transcripts exist. Several smaller clusters of IFNT variants were also seen within these larger goat clusters. Clustering also occurred in the sheep and cow variants. Some clusters of IFNT variants contain only a few members, whereas other clusters contain many. No breed-dependency is apparent for these alleles in any species, but further work is needed to explore this possible explanation for the multitude of polymorphisms. It also is interesting to note that most IFNT variants have appeared recently in ruminants (Fig. 3). The rapid timescale for the evolution of these expansive clusters of related IFNT variants are suggestive of gene conversion events, where crossover recombination events transfer genetic material from one chromosome to the other (Cole et al. 2012). In the case of intron-less genes like IFNT and other type I IFNs, the entire gene can be recombined to generate highly similar but novel alleles.

Only a subset of these nucleotide polymorphisms will modify the primary AA sequence of IFNT. Bovine IFNT variants have been the best studied in this regard (Walker \& Roberts 2009). In most gene variant to variant comparisons, the incidence of synonymous nucleotide changes (no change in AA codon read) usually is either equal to or greater than the rate of acquisitions of nonsynonymous changes (change in codon read). This suggests that the open reading frames of the IFNTS are no longer under strong selective pressure to change primary AA sequence to greatly affect potency or stability. Rather, most of the variation between IFNT isoforms appears to be consistent with purifying selection.

\section{Why are there so many IFNT genes and gene variants?}

The reason why there is a need for several IFNT genes in ruminants has been the topic of much research over the past 20 years. Several theories have been put forth. As noted in the previous section, multiple genes may exist to maximize IFNT production during early pregnancy. IFNT is the most abundant transcript and protein during the peri-implantation period. Hundreds of micrograms of IFNT is produced by a single elongated conceptus during peak production (Godkin et al. 1982, Ashworth \& Bazer 1989). Alternatively, perhaps multiple genes are needed to ensure adequate coverage of IFNT activity as conceptuses develop and circumstances change in the uterus as it prepares for placental attachment. In cattle, two IFNT genes are transcribed more highly than other genes at the blastocyst stage, but the expression of several additional IFNT variants are upregulated as conceptus development advances (Walker \& Roberts 2009). Also, differences exist in the abundance of at least two ovine IFNT transcripts when conceptuses are undergoing implantation (Sakurai et al. 2013).

Another reason why multiple IFNT genes may exist is that they encode for proteins with different biological potencies. The polygenic nature of type I IFNs as antiviral agents has afforded IFNs with the ability to evolve and adapt to their ever-changing environment and viral insults (Goodbourn et al. 2000). Perhaps this same permissive nature for gene duplication and mutation has provided IFNT genes with heightened abilities to serve as pregnancy recognition factors. IFNT protein variants differ in antiviral and antiproliferative activities (Martal et al. 1990Fillion et al. 1991, Ott et al. 1991, Alexenko et al. 1999, Winkelman et al. 1999). Also, prostaglandin (PG) production in cultured bovine endometrial cells is regulated to different extents by different IFNT variants (Parent et al. 2003). Most of the bovine and ovine IFNT variants studied thus far were proficient at reducing PGE and PGF2 $\alpha$ concentrations when added to cultures at low concentrations, but preferentially stimulated PGE2 production at higher concentrations. One bolFNT variant inhibited PGE2 production at all concentrations while another stimulated both PGE and PGF2 $\alpha$ at high concentrations. There likely are several other key physiological events that could be manipulated differently by different IFNT variants. IFNT-responsive genes in the ovine uterus are involved in controlling apoptosis, cellular growth, angiogenesis, vasculogenesis, inflammation and several other processes (Chen et al. 2006, 2007, Gray et al. 2006). There is no information available on how specific IFNT variants might control the signaling networks that operate these diverse biological processes.

There is evidence that IFNT variants differ in their antiluteolytic potency. An adequate in vitro model for antiluteolytic activity has not been developed, 
Table 1 Minimal effective amounts of Ovis aries IFNT and IFNA recombinant proteins at extending estrous cycle lengths in cyclic ewes*.

\begin{tabular}{lcc}
\hline & \multicolumn{2}{c}{$\begin{array}{l}\text { Minimally effective amount needed to extend } \\
\text { estrous cycle length in cyclic ewes*** }\end{array}$} \\
\cline { 2 - 3 } Protein name** & Protein $(\mu$ g/day) & Antiviral Activity (IU/day) \\
\hline IFNT4 (p3) & 10 & $0.7 \times 10^{7}$ \\
IFNT2c (p8) & 50 & $1.7 \times 10^{7}$ \\
IFNT1a (OTP-1) & 100 & $1.0 \times 10^{7}$ \\
IFNT2c (trophoblastin) & 340 & $1.9 \times 10^{7}$ \\
IFNT6c (p6) & 300 & $4.3 \times 10^{7}$ \\
IFNT11 (s4) & 1000 & $11.8 \times 10^{7}$ \\
IFNA1 & 175 & $0.7 \times 10^{7}$ \\
\hline
\end{tabular}

*Data were taken from various sources from work completed by the same laboratory over several years (Ealy et al. 1998a,b, Martal et al. 1990, Ott et al. 1993, Winkelman et al. 1999, Green et al. 2005); **Nomenclature used for naming these IFNs is provided in (Alexenko et al. 2000). GenBank accession numbers and associated sequences in Fig. 3 are as follows. IFNT4 (X56341.1; sheep 7), IFNT2c (X07920.1 for p8; M26386 for trophoblastin; sheep 10), IFNT1a (Y00287 and NM-001123399; sheep 9), IFNT6c (X56343.1; sheep 22), IFNT11 (M73241.1; sheep 1), IFNA (AY802984; NA); ***The uterine horn ipsilateral to a functional corpus luteum was cannulated. The cannula was exteriorized at the flank. Twice daily injections, each containing one-half the daily amount of IFN, was given. The tubing was flushed with carrier solution to ensure complete delivery of the protein.

so that studies defining the potency of IFNT variants have utilized an animal model that involves surgical placement of uterine cannulas into cyclic ewes and daily IFNT injections during diestrus. The maintenance of elevated circulating progesterone concentrations is used as the indicator of how long $C L$ lifespan and subsequent estrous cycle length were extended. Table 1 shows the minimal effective amounts of IFNT needed to extend luteal function in several independent studies (Ealy et al. 1998a,b, Martal et al. 1990, Ott et al. 1993, Winkelman et al. 1999, Green et al. 2005). When examining protein potencies based on the amount of IFNT protein administered, the IFNT4 variant was clearly more effective than other IFNT proteins at extending CL function. A related variant termed IFNT2C, which differs in only 3 AAs from IFNT4, required 5- to 34-times more protein to achieve the same effect, depending on the recombinant protein used. A more distinct variant, termed IFNT6c, required 30-times more protein to achieve this effect. A fourth IFNT protein, termed IFNT11 (formerly known as IFNT-s4/p4) was not a potent antiluteolytic factor. This protein was studied because recombinant protein could be produced in great quantities from reconstituted bacterial inclusion bodies (i.e. insoluble protein pellet) (Li \& Roberts 1994b, Niswender et al. 1997). Although the 5' UTR of IFNT11 resembles that of other IFNT, its coding region contains similarity with both IFNT and IFNW (Leaman et al. 1992, Walker \& Roberts 2009). It also is lowly expressed in ovine conceptuses, likely because it lacks a functional Ets2 site (Ezashi et al. 1998). Interestingly, despite its lack of effectiveness in extending estrous cycle length, IFNT11 is a potent antiviral and antiproliferative agent (Ealy et al. 1998b, Alexenko et al. 1999). Therefore, whatever mutations have caused it to lose its antiluteolytic potential has not interfered with its ability to function as an immuneregulatory factor. A recombinant ovine IFNA protein also contained antiluteolytic activity, but more of it was needed to produce an antiluteolytic response than with IFNT4 and IFNT2c (Table 1) (Green et al. 2005).

There has been some debate as to whether antiviral activity can be used as a guide to investigate antiluteolytic potential. Complicating this issue is that the purity, stability to freeze thawing (not recommended) and biological shelf lives of recombinant IFN proteins may vary from batch to batch and protein to protein. Accordingly, all IFNs should probably be assessed for antiviral activity before beginning an experiment. However, antiviral activity is not associated with antiluteolytic activity. The antiviral potency of type I IFNs also has very little merit on how it will perform as an antiproliferative or immunomodulatory factor (Ealy et al. 1998b, Winkelman et al. 1999).

It is noteworthy to also mention there is a good deal of biological variation in individual ewe responses in regard to the length of time before ewes return to estrus after an IFNT treatment (Ealy et al. 1998a,b, Winkelman et al. 1999, Green et al. 2005). Most IFNT treatment groups contain ewes that (1) do not respond, (2) have a modest response $(<21$ day interestrous interval) or (3) have a good response to the treatment ( 21 to $>40$ day interestrous interval) (Green et al. 2005). Usually 5-15\% of treated ewes fail to respond to an otherwise adequate IFNT treatment. These ewes may represent ewes that would undergo early conceptus loss because they are incapable of responding to IFNT. The proportion of modest and good responders changes based on the type and dose of IFN treatment given. For example, a greater proportion of ewes exhibited $>21$ day interestrous intervals when treated with ovIFNT4 $(10 \mu \mathrm{g} /$ day $)$ than when treated with ovIFNA ( $175 \mu \mathrm{g} /$ day) $(67 \%$ vs $25 \%$ good responders respectively) (Green et al. 2005). Also, there appears to be an association between the length of IFNT treatment and the length of extended $\mathrm{CL}$ function. Ewes provided IFNT until day 18 or 25 post-estrus were more likely to exhibit estrous cycle extension that lasted $\geq 40$ days (Spencer et al. 1999, Green et al. 2005) than ewes only treated up to day 15 or 16 post-estrus (Ealy et al. 1998b, Winkelman et al. 1999). One explanation for this phenomenon is that there may be two important facets to IFNT action during early pregnancy. The first includes the initial rescue of the $\mathrm{CL}$ and the second involves other uterine- and/or ovarian-dependent actions that maintain $\mathrm{CL}$ function for several weeks. Perhaps the comprehensive uterine and ovarian responses to IFNT enable this second set of actions to prolong the period of pseudopregnancy observed in ewes. 


\section{Concluding remarks}

The intention of this review has been to provide a sufficient perspective on the vast amount of knowledge gained in the past 30 years about the evolution of IFNT. The crucial step that created the primordial gene encoding IFNT probably occurred when a trophoblastspecific promoter/enhancer was inserted into the gene control regions of an ancestral IFNW. Subsequent point mutations, duplications and conversion events have led to the present complement of contemporary IFNT genes, which appear to comprise as few as three but as many as seven in cattle. Cattle, sheep and goats also contain numerous polymorphic forms of IFNT. There is compelling evidence that these different forms do not have identical, biological activities, including their abilities to extend estrous cycle length. Several questions about the need for so many IFNT variants still remain unanswered. Among them is characterizing the full extent of individual and combined IFNT protein actions in the uterus.

\section{Supplementary data}

This is linked to the online version of the paper at http://dx.doi. org/10.1530/REP-17-0292.

\section{Declaration of interest}

The authors declare that there is no conflict of interest that could be perceived as prejudicing the impartiality of this anniversary review.

\section{Funding}

Work presented in this review did not receive any specific grant from any funding agency in the public, commercial or not-for-profit sector.

\section{Acknowledgements}

Authors thank Dr R Michael Roberts for inviting us to contribute to this special issue. Authors also thank Dr Jonathan A Green (University Missouri, Columbia) for reviewing this article before its submission.

\section{References}

Alexenko AP, Ealy AD \& Roberts RM 1999 The cross-species antiviral activities of different IFN-tau subtypes on bovine, murine, and human cells: contradictory evidence for therapeutic potential. Journal of Interferon and Cytokine Research 19 1335-1341. (doi:10.1089/107999099312795)

Alexenko AP, Ealy AD, Bixby JA \& Roberts RM 2000 A classification for the interferon-tau. Journal of Interferon and Cytokine Research 20 817-822. (doi:10.1089/10799900050151085)

Ank N, Iversen MB, Bartholdy C, Staeheli P, Hartmann R, Jensen UB, Dagnaes-Hansen F, Thomsen AR, Chen Z, Haugen H et al. 2008 An important role for type III interferon (IFN-lambda/IL-28) in TLR-induced antiviral activity. Journal of Immunology 180 2474-2485. (doi:10.4049/ jimmunol.180.4.2474)

Ashworth CJ \& Bazer FW 1989 Changes in ovine conceptus and endometrial function following asynchronous embryo transfer or administration of progesterone. Biology of Reproduction 40 425-433. (doi:10.1095/biolreprod40.2.425)

Bach EA, Aguet M \& Schreiber RD 1997 The IFN gamma receptor: a paradigm for cytokine receptor signaling. Annual Review of Immunology 15 563-591. (doi:10.1146/annurev.immunol.15.1.563)

Baldauf SL 2003 Phylogeny for the faint of heart: a tutorial. Trends in Genetics 19 345-351. (doi:10.1016/S0168-9525(03)00112-4)

Bayer A, Lennemann NJ, Ouyang Y, Bramley JC, Morosky S, Marques ET Jr, Cherry S, Sadovsky Y \& Coyne CB 2016 Type III interferons produced by human placental trophoblasts confer protection against Zika virus infection. Cell Host and Microbe 19 705-712. (doi:10.1016/j. chom.2016.03.008)

Bazer FW 1989 Establishment of pregnancy in sheep and pigs. Reproduction, Fertility, and Development 1 237-242. (doi:10.1071/ RD9890237)

Bazer FW, Spencer TE, Johnson GA, Burghardt RC \& Wu G 2009 Comparative aspects of implantation. Reproduction 138 195-209. (doi:10.1530/REP-09-0158)

Billiau A \& Matthys P 2009 Interferon-gamma: a historical perspective. Cytokine and Growth Factor Reviews 20 97-113. (doi:10.1016/j. cytogfr.2009.02.004)

Charpigny G, Reinaud P, Huet JC, Guillomot M, Charlier M, Pernollet JC \& Martal J 1988 High homology between a trophoblastic protein (trophoblastin) isolated from ovine embryo and alpha-interferons. FEBS Letters 228 12-16. (doi:10.1016/0014-5793(88)80574-X)

Chen Y, Green JA, Antoniou E, Ealy AD, Mathialagan N, Walker AM, Avalle MP, Rosenfeld CS, Hearne LB \& Roberts RM 2006 Effect of interferontau administration on endometrium of nonpregnant ewes: a comparison with pregnant ewes. Endocrinology 147 2127-2137. (doi:10.1210/ en.2005-1310)

Chen Y, Antoniou E, Liu Z, Hearne LB \& Roberts RM 2007 A microarray analysis for genes regulated by interferon-tau in ovine luminal epithelial cells. Reproduction 134 123-135. (doi:10.1530/REP-07-0387)

Cochet M, Vaiman D \& Lefevre F 2009 Novel interferon delta genes in mammals: cloning of one gene from the sheep, two genes expressed by the horse conceptus and discovery of related sequences in several taxa by genomic database screening. Gene 433 88-99. (doi:10.1016/j. gene.2008.11.026)

Cole F, Keeney S \& Jasin M 2012 Preaching about the converted: how meiotic gene conversion influences genomic diversity. Annals of the New York Academy of Sciences 1267 95-102. (doi:10.1111/j.17496632.2012.06595.x)

Crespi B \& Semeniuk C 2004 Parent-offspring conflict in the evolution of vertebrate reproductive mode. American Naturalist 163 635-653. (doi:10.1086/382734)

Cross JC \& Roberts RM 1989 Porcine conceptuses secrete an interferon during the preattachment period of early pregnancy. Biology of Reproduction 40 1109-1118. (doi:10.1095/biolreprod40.5.1109)

Cross JC, Farin CE, Sharif SF \& Roberts RM 1990 Characterization of the antiviral activity constitutively produced by murine conceptuses: absence of placental mRNAs for interferon alpha and beta. Molecular Reproduction and Development 26 122-128. (doi:10.1002/ mrd.1080260205)

Ealy AD, Alexenko AP, Keisler DH \& Roberts RM 1998a Loss of the signature six carboxyl amino acid tail from ovine interferon-tau does not affect biological activity. Biology of Reproduction 58 1463-1468. (doi:10.1095/biolreprod58.6.1463)

Ealy AD, Green JA, Alexenko AP, Keisler DH \& Roberts RM 1998b Different ovine interferon-tau genes are not expressed identically and their protein products display different activities. Biology of Reproduction $\mathbf{5 8}$ 566-573. (doi:10.1095/biolreprod58.2.566)

Ealy AD, Larson SF, Liu L, Alexenko AP, Winkelman GL, Kubisch HM, Bixby JA \& Roberts RM 2001 Polymorphic forms of expressed bovine interferon-tau genes: relative transcript abundance during early placental development, promoter sequences of genes and biological activity of protein products. Endocrinology 142 2906-2915. (doi:10.1210/ endo.142.7.8249) 
Ezashi T, Ealy AD, Ostrowski MC \& Roberts RM 1998 Control of interferontau gene expression by Ets-2. PNAS 95 7882-7887. (doi:10.1073/ pnas.95.14.7882)

Fillion C, Chaouat G, Reinaud P, Charpigny JC \& Martal J 1991 Immunoregulatory effects of ovine trophoblastin protein (OTP): all five isoforms suppress PHA-induced lymphocyte proliferation. Journal of Reproductive Immunology 19 237-249. (doi:10.1016/01650378(91)90038-R)

Fowden AL \& Constancia M 2012 Maternal-fetal resource allocation. Placenta 33 (Supplement 2) e1-e2. (doi:10.1016/j.placenta.2012.09.005)

Freese CH, Aune KE, Boyd DP, Derr JN, Forrest SC, Gates CC, Gogan PJP, Grassel SM, Halbert ND, Kunkel K et al. 2007 Second chance for plains bison. Biological Conservation 136 175-184. (doi:10.1016/j. biocon.2006.11.019)

Gad, HH, Dellgren C, Hamming OJ, Vends S, Paludan SR \& Hartmann R 2009 Interferon-lambda is functionally an interferon but structurally related to the interleukin-10 family. Journal of Biological Chemistry 284 20869-20875. (doi:10.1074/jbc.M109.002923)

Galani IE, Koltsida O \& Andreakos E 2015 Type III interferons (IFNs): emerging master regulators of immunity. Advances in Experimental Medicine and Biology 850 1-15. (doi:10.1007/978-3-319-15774-0 1)

Godkin JD, Bazer FW, Moffatt J, Sessions F \& Roberts RM 1982 Purification and properties of a major, low molecular weight protein released by the trophoblast of sheep blastocysts at day 13-21. Journal of Reproduction and Fertility 65 141-150. (doi:10.1530/jrf.0.0650141)

Godkin JD, Bazer FW \& Roberts RM 1984a Ovine trophoblast protein 1, an early secreted blastocyst protein, binds specifically to uterine endometrium and affects protein synthesis. Endocrinology 114 120-130. (doi:10.1210/endo-114-1-120)

Godkin JD, Bazer FW, Thatcher WW \& Roberts RM 1984b Proteins released by cultured Day 15-16 conceptuses prolong luteal maintenance when introduced into the uterine lumen of cyclic ewes. Journal of Reproduction and Fertility 71 57-64. (doi:10.1530/jrf.0.0710057)

Goodbourn S, Didcock L \& Randall RE 2000 Interferons: cell signalling, immune modulation, antiviral response and virus countermeasures. Journal of General Virology 81 2341-2364. (doi:10.1099/0022-131781-10-2341)

Gray CA, Abbey CA, Beremand PD, Choi Y, Farmer JL, Adelson DL, Thomas TL, Bazer FW \& Spencer TE 2006 Identification of endometrial genes regulated by early pregnancy, progesterone, and interferon tau in the ovine uterus. Biology of Reproduction 74 383-394. (doi:10.1095/ biolreprod.105.046656)

Green MP, Spate LD, Bixby JA, Ealy AD \& Roberts RM 2005 A comparison of the anti-luteolytic activities of recombinant ovine interferon-alpha and -tau in sheep. Biology of Reproduction 73 1087-1093. (doi:10.1095/ biolreprod.105.043406)

Hansen PJ 1997 Interactions between the immune system and the bovine conceptus. Theriogenology 47 121-130. (doi:10.1016/S0093691X(96)00346-9)

Hedrick PW 2009 Conservation genetics and North American bison (Bison bison). Journal of Heredity 100 411-420. (doi:10.1093/jhered/esp024)

Hemberger M 2013 Immune balance at the foeto-maternal interface as the fulcrum of reproductive success. Journal of Reproductive Immunology 97 36-42. (doi:10.1016/j.jri.2012.10.006)

Hughes AL 1995 The evolution of the type I interferon gene family in mammals. Journal of Molecular Evolution 41 539-548.

Imakawa K, Anthony RV, Kazemi M, Marotti KR, Polites HG \& Roberts RM 1987 Interferon-like sequence of ovine trophoblast protein secreted by embryonic trophectoderm. Nature 330 377-379. (doi:10.1038/330377a0)

Imakawa K, Hansen TR, Malathy PV, Anthony RV, Polites HG, Marotti KR \& Roberts RM 1989 Molecular cloning and characterization of complementary deoxyribonucleic acids corresponding to bovine trophoblast protein-1: a comparison with ovine trophoblast protein-1 and bovine interferon-alpha II. Molecular Endocrinology 3 127-139. (doi:10.1210/mend-3-1-127)

Imakawa K, Kim MS, Matsuda-Minehata F, Ishida S, lizuka M, Suzuki M, Chang KT, Echternkamp SE \& Christenson RK 2006 Regulation of the ovine interferon-tau gene by a blastocyst-specific transcription factor, Cdx2. Molecular Reproduction and Development 73 559-567. (doi:10.1002/mrd.20457)
Klein C \& Troedsson MH 2011 Maternal recognition of pregnancy in the horse: a mystery still to be solved. Reproduction, Fertility, and Development 23 952-963. (doi:10.1071/RD10294)

Krause CD \& Pestka S 2005 Evolution of the class 2 cytokines and receptors, and discovery of new friends and relatives. Pharmacology and Therapeutics 106 299-346. (doi:10.1016/j.pharmthera.2004.12.002)

Kubisch HM, Sirisathien S, Bosch P, Hernandez-Fonseca HJ, Clements G, Liukkonen JR \& Brackett BG 2004 Effects of developmental stage, embryonic interferon-tau secretion and recipient synchrony on pregnancy rate after transfer of in vitro produced bovine blastocysts. Reproduction in Domestic Animals 39 120-124. (doi:10.1111/j.14390531.2004.00491.x)

Lawson RA, Rowson LE, Moor RM \& Tervit HR 1975 Experiments on egg transfer in the cow and ewe: dependence of conception rate on the transfer procedure and stage of the oestrous cycle. Journal of Reproduction and Fertility 45 101-107. (doi:10.1530/jrf.0.0450101)

Leaman DW \& Roberts RM 1992 Genes for the trophoblast interferons in sheep, goat, and musk ox and distribution of related genes among mammals. Journal of Interferon Research 12 1-11. (doi:10.1089/ jir.1992.12.1)

Leaman DW, Cross JC \& Roberts RM 1992 Genes for the trophoblast interferons and their distribution among mammals. Reproduction, Fertility, and Development 4 349-353. (doi:10.1071/RD9920349)

Lefevre F, Guillomot M, D'Andrea S, Battegay S \& La Bonnardiere C 1998a Interferon-delta: the first member of a novel type I interferon family. Biochimie 80 779-788. (doi:10.1016/S0300-9084(99)80030-3)

Lefevre F, Martinat-Botte F, Locatelli A, De Niu P, Terqui M \& La Bonnardiere C $1998 b$ Intrauterine infusion of high doses of pig trophoblast interferons has no antiluteolytic effect in cyclic gilts. Biology of Reproduction 58 1026-1031. (doi:10.1095/biolreprod58.4.1026)

Letunic I \& Bork P 2016 Interactive tree of life (iTOL) v3: an online tool for the display and annotation of phylogenetic and other trees. Nucleic Acids Research 44 W242-W245. (doi:10.1093/nar/gkw290)

Levraud JP, Boudinot P, Colin I, Benmansour A, Peyrieras N, Herbomel P \& Lutfalla G 2007 Identification of the zebrafish IFN receptor: implications for the origin of the vertebrate IFN system. Journal of Immunology $\mathbf{1 7 8}$ 4385-4394. (doi:10.4049/jimmunol.178.7.4385)

Li J \& Roberts RM 1994a Interferon-tau and interferon-alpha interact with the same receptors in bovine endometrium. Use of a readily iodinatable form of recombinant interferon-tau for binding studies. Journal of Biological Chemistry $26913544-13550$.

Li J \& Roberts RM $1994 b$ Structure-function relationships in the interferon-tau (IFN-tau). Changes in receptor binding and in antiviral and antiproliferative activities resulting from site-directed mutagenesis performed near the carboxyl terminus. Journal of Biological Chemistry $26924826-24833$.

Martal J, Lacroix MC, Loudes C, Saunier M \& Wintenberger-Torres S 1979 Trophoblastin, an antiluteolytic protein present in early pregnancy in sheep. Journal of Reproduction and Fertility 56 63-73. (doi:10.1530/ jrf.0.0560063)

Martal J, Degryse E, Charpigny G, Assal N, Reinaud P, Charlier M, Gaye P \& Lecocq JP 1990 Evidence for extended maintenance of the corpus luteum by uterine infusion of a recombinant trophoblast alphainterferon (trophoblastin) in sheep. Journal of Endocrinology 127 R5-R8. (doi:10.1677/joe.0.127R005)

Moor RM \& Rowson LE 1964 Influence of the embryo and uterus on luteal function in the sheep. Nature 201 522-523. (doi:10.1038/201522a0)

Moor RM \& Rowson LE 1966 The corpus luteum of the sheep: effect of the removal of embryos on luteal function. Journal of Endocrinology 34 497-502. (doi:10.1677/joe.0.0340497)

Niswender KD, Li J, Powell MR, Loos KR, Roberts RM, Keisler DH \& Smith MF 1997 Effect of variants of interferon-tau with mutations near the carboxyl terminus on luteal life span in sheep. Biology of Reproduction 56 214-220. (doi:10.1095/biolreprod56.1.214)

Ott TL, Van Heeke G, Johnson HM \& Bazer FW 1991 Cloning and expression in Saccharomyces cerevisiae of a synthetic gene for the type-I trophoblast interferon ovine trophoblast protein-1: purification and antiviral activity. Journal of interferon research 11 357-364. (doi:10.1089/jir.1991.11.357)

Ott TL, Van Heeke G, Hostetler CE, Schalue TK, Olmsted J, Johnson HM \& Bazer FW 1993 Intrauterine injection of recombinant ovine 
interferon-tau extends the interestrous interval in sheep. Theriogenology 40 757-769. (doi:10.1016/0093-691X(93)90211-M)

Parent J, Villeneuve C, Alexenko AP, Ealy AD \& Fortier MA 2003 Influence of different isoforms of recombinant trophoblastic interferons on prostaglandin production in cultured bovine endometrial cells. Biology of Reproduction 68 1035-1043. (doi:10.1095/biolreprod.102.008250)

Pestka S, Langer JA, Zoon KC \& Samuel CE 1987 Interferons and their actions. Annual Review of Biochemistry 56 727-777. (doi:10.1146/ annurev.bi.56.070187.003455)

Pestka S, Krause CD \& Walter MR 2004 Interferons, interferon-like cytokines, and their receptors. Immunological Reviews 202 8-32. (doi:10.1111/j.0105-2896.2004.00204.x)

Rajaravindra KS, Mitra A, Sharma AK, Deb SM \& Sharma A 2006 Molecular characterization of the interferon-tau gene of the mithun (Bos frontalis). Zoological Science 23 607-611. (doi:10.2108/zsj.23.607)

Rawn SM \& Cross JC 2008 The evolution, regulation, and function of placenta-specific genes. Annual Review of Cell and Developmental Biology 24 159-181. (doi:10.1146/annurev.cellbio.24.110707.175418)

Roberts RM 2007 Interferon-tau, a Type 1 interferon involved in maternal recognition of pregnancy. Cytokine and Growth Factor Reviews $\mathbf{1 8}$ 403-408. (doi:10.1016/j.cytogfr.2007.06.010)

Roberts RM, Cross JC \& Leaman DW 1992a Interferons as hormones of pregnancy. Endocrine Reviews 13 432-452.(doi:10.1210/er.13.3.432)

Roberts RM, Leaman DW \& Cross JC 1992b Role of interferons in maternal recognition of pregnancy in ruminants. Proceedings of the Society for Experimental Biology and Medicine 200 7-18. (doi:10.3181/00379727200-43387A)

Roberts RM, Liu L \& Alexenko A 1997 New and atypical families of type I interferons in mammals: comparative functions, structures, and evolutionary relationships. Progress in Nucleic Acid Research and Molecular Biology 56 287-325. (doi:10.1016/s0079-6603(08)61008-9)

Roberts RM, Liu L, Guo Q, Leaman D \& Bixby J 1998 The evolution of the type I interferons. Journal of Interferon and Cytokine Research $\mathbf{1 8}$ 805-816. (doi:10.1089/jir.1998.18.805)

Roberts RM, Ezashi T, Rosenfeld CS, Ealy AD \& Kubisch HM 2003 Evolution of the interferon tau genes and their promoters, and maternaltrophoblast interactions in control of their expression. Reproduction Supplement 61 239-251.

Roberts RM, Chen Y, Ezashi T \& Walker AM 2008 Interferons and the maternal-conceptus dialog in mammals. Seminars in Cell and Developmental Biology 19 170-177. (doi:10.1016/j.semcdb.2007.10.007)

Roberts RM, Green JA \& Schulz LC 2016 The evolution of the placenta. Reproduction 152 R179-R189. (doi:10.1530/REP-16-0325)

Rowson LE \& Moor RM 1967 The influence of embryonic tissue homogenate infused into the uterus, on the life-span of the corpus luteum in the sheep. Journal of Reproduction and Fertility 13 511-516. (doi:10.1530/ jrf.0.0130511)
Rowson LE, Moor RM \& Lawson RA 1969 Fertility following egg transfer in the cow; effect of method, medium and synchronization of oestrus. Journal of Reproduction and Fertility 18 517-523. (doi:10.1530/ jrf.0.0180517)

Sakurai T, Nakagawa S, Kim MS, Bai H, Bai R, Li J, Min KS, Ideta A, Aoyagi Y \& Imakawa K 2013 Transcriptional regulation of two conceptus interferon tau genes expressed in Japanese black cattle during periimplantation period. PLOS ONE 8 e80427. (doi:10.1371/journal. pone.0080427)

Sang Y, Bergkamp J \& Blecha F 2014 Molecular evolution of the porcine type I interferon family: subtype-specific expression and antiviral activity. PLOS ONE 9 e112378. (doi:10.1371/journal.pone.0112378)

Sheppard P, Kindsvogel W, Xu W, Henderson K, Schlutsmeyer S, Whitmore TE, Kuestner R, Garrigues U, Birks C, Roraback J et al. 2003 IL-28, IL-29 and their class II cytokine receptor IL-28R. Nature Immunology 4 63-68. (doi:10.1038/ni873)

Spencer TE, Gray A, Johnson GA, Taylor KM, Gertler A, Gootwine E, Ott TL \& Bazer FW 1999 Effects of recombinant ovine interferon tau, placental lactogen, and growth hormone on the ovine uterus. Biology of Reproduction 61 1409-1418. (doi:10.1095/biolreprod61.6.1409)

Spencer TE, Burghardt RC, Johnson GA \& Bazer FW 2004 Conceptus signals for establishment and maintenance of pregnancy. Animal Reproduction Science 82-83 537-550. (doi:10.1016/j.anireprosci.2004.04.014)

Tamura K \& M Nei 1993 Estimation of the number of nucleotide substitutions in the control region of mitochondrial DNA in humans and chimpanzees. Molecular Biology and Evolution 10 512-526.

Walker AM \& Roberts 2009 Characterization of the bovine type I IFN locus: rearrangements, expansions, and novel subfamilies. BMC Genomics 10 187. (doi:10.1186/1471-2164-10-187)

Winkelman GL, Roberts RM, James PA, Alexenko AP \& Ealy AD 1999 Identification of the expressed forms of ovine interferon-tau in the periimplantation conceptus: sequence relationships and comparative biological activities. Biology of Reproduction 61 1592-1600. (doi:10.1095/biolreprod61.6.1592)

Ziecik AJ 2002 Old, new and the newest concepts of inhibition of luteolysis during early pregnancy in pig. Domestic Animal Endocrinology 23 265-275. (doi:10.1016/S0739-7240(02)001625)

Received 13 May 2017

First decision 5 June 2017

Revised manuscript received 20 June 2017

Accepted 10 July 2017 